\title{
Management of Solid Biomass in Medium Power Boiler Plants
}

\author{
Elżbieta Rybak-Wilusz*, Danuta Proszak-Miąsik', Bartosz Kuliński² \\ 1 Rzeszow University of Technology, Faculty of Civil and Environmental Engineering and Architecture, \\ Department of Heat Engineering and Air Conditioning, 12 Powstańców Warszawy Street, 35-959 Rzeszow, \\ Poland \\ 2 Presystem Ltd., Zamkowa 2/6 Street, 35-032 Rzeszow, Poland \\ * Corresponding author's e-mail: elrywi@prz.edu.pl
}

\begin{abstract}
Solid biomass plays a leading role in the development and dissemination of technologies pertaining to the usage of renewable raw materials. The biomass processed into solid biofuel requires special logistic operations. Distribution from the place of production, handling and storage of biofuel are basic and necessary elements of the chain of fuel supply to the energy source. Solid biofuels for energy use occur in different forms which affect the costs of logistic operations. Rational heat generation requires choosing a specific type and form of biofuel, assessing the availability of raw materials, integrating fuel management with energy source technology and, above all, determining the cost of energy generation. The cost of energy generation includes the cost of fuel and logistic operations, which depend mainly on a type and form of fuel. Currently, the commonly used biofuels are wood chips, straw and pellets. This paper presents a comparison of heat demand of $400 \mathrm{~kW}, 600 \mathrm{~kW}$ and $1 \mathrm{MW}$ boiler plants generating heat for the purpose of heating buildings and water. The analysis took into account three forms of biofuels: compressed, crushed and granulated forms resulting from different types of biomass (straw, woodchips, pellets). The cost of heat generation in the aspect of biofuel management and the share of particular cost components in heat production were determined. It was shown that in medium power boiler plants, the granulated fuel has the lowest cost of biomass distribution, whereas wood chips have the lowest cost of heat production.
\end{abstract}

Keywords: solid biofuels, heat demand, biomass consumption, costs of heat generation

\section{INTRODUCTION}

The structure of use and technologies of processing primary energy carriers are one of the basic characteristics of economic development. The dissemination of renewable energy (RE) causes a constant increase in the usage of renewable raw materials and carriers and, among others (solar, wind, water and geothermal energy), biomass is the largest potential renewable energy source, both in Poland and worldwide. The general percentage of renewable energy in the total worldwide consumption of energy in 2017 was approximately $18.1 \%$ (including $7.5 \%$ of traditional biomass and $10.6 \%$ of modern energy sources which use biomass as well) (Renewables 2019). In Poland, in 2017 the rate of renewable energy percentage in the gross final energy consumption was $11 \%$ (decreased by $0.7 \%$ compared to 2015 ) (Renewable 2018a). The percentage of solid biomass in acquiring renewable energy in 2017 was $67.9 \%$ (42\% in EU states) (Renewable 2018b). Therefore, bioenergy and its main raw materials, solid biofuels, may be considered as the basic renewable energy carrier both in the world and in Poland. Moreover, world statistics (Renewables 2019) show that biomass is more and more popular among its potential users. Additionally, the increase of biofuel production and bioenergy production is stimulated by tax exempts, subsidies and other forms of assistance to investors (Renewables 2019).

Biomass is an organic material created in the process of photosynthesis in participation with solar radiation, which enables life on Earth and serves, inter alia, as food for the living organisms. 
In the contemporary world, the failure to use the significant excess of biomass and widely introduced intentional cultivation of energy crops result in the fact that biomass is presently the main raw material of primary renewable energy. The biomass for energy use is a biological substance which is a part of products, waste or remains from agriculture and forestry, coming from energy crops and the plant processing industry. Processing to a biofuel for energy use includes woodchips, compressed straw, pellets, briquettes and biochar (Renewable 2018c). The large percentage of biomass in the production of renewable energy in Poland results from the favourable geographical conditions (Bentsen et al. 2014), such as climate, soil, agricultural and forest infrastructure. Poland has a significant potential of agricultural and forest resources, developed agricultural and food processing industry, wood processing industry and the possibility to import the biomass from the neighbouring countries. In 2018, the farmlands in Poland covered $47 \%$ of the country surface (crop growing area was 34.5\%; 10.8 million ha) (Agriculture 2019) and woods covered 29.6\% of the country in 2017 (www.lasy.gov.pl 2019).

The usage of biomass coming from plants for energy purposes is connected with converting it to derivative energy carriers, i.e. heat and electricity. Compared to other renewable technologies, biomass requires a complex process of raw material supply, transformation into biofuel and conversion to bioenergy (in the process of direct combustion or transformation to the form of liquid and gas fuels). Numerous and diversified potential raw materials as well as the need to collect, store and process them require drawing attention to the management of solid biofuels in heat sources.

The purpose of this paper was to analyse the biomass management in medium power boiler plants in the aspect of heat production presented with straw, woodchips and pellets as examples representing three characteristic forms of solid biofuels: compressed, crushed and granulated ones, and to present the relationships between the distribution costs and total costs of heat production.

\section{FUEL MANAGEMENT IN BOILER PLANT}

Fuel management in the boiler plant includes the supply of fuel to the store, handing, storing, sometimes drying and transporting it to boilers and removing ashes. In the heat production system, the type of biofuel affects the choice of boilers and particular types of mutually related and cooperating elements of logistic operations. The transport from the place of production, adjusted to the needs of the boiler location, fuel handling and sometimes direct storage are basic and necessary elements of the chain of fuel supply to the energy source. Additionally, the system requires many additional devices such as loading and unloading equipment, storing tanks and surfaces as well as equipment for in-plant transport. Calorific value is a clear-cut parameter characterizing the suitability of fuel for energy purposes which, to a significant degree, depends on humidity. Therefore, transport and handling conditions and, above all, storing time and conditions affect the quality of fuel which goes through the combustion process. The manner in which the fuel is stored, the type and size of the warehouse and fuel drying are determined by the time of using fuel for power purposes (for the whole year or seasonally) and, above all, by the form of biomass and its physical parameters.

Rational heat production requires the selection of a specific type and form of biofuel, taking into account the raw material availability and integration of fuel management with the energy source technology. The economic analysis allows selecting the optimum fuel in the aspect of financial factors. However, it should be noted that the cost of supply chain and technology for converting biomass into useful forms of energy may limit the increase in the use of biomass in energy supply (Rentizelas et al. 2009).

\section{ASSUMPTIONS FOR CALCULATIONS}

The storage area and type of equipment used depend on the type and consumption of fuel. The calculations were performed for three types of biomass: woodchips, pellets and straw with the parameters described in Table 1.

Woodchips and pellets are wooden material, woodchips are a crushed form, whereas pellets in a granulated form. Straw in a compressed form, forming bales with the following dimensions: $1.8 \mathrm{~m} ; 1.2 \mathrm{~m} ; 0.7 \mathrm{~m}$. The boiler plant produces the heat for heating buildings and water. The boiler plant power $Q_{k}$ for heating purposes is $400 \mathrm{~kW}$, $600 \mathrm{~kW}$ and $1000 \mathrm{~kW}$. The boiler plant works in 
Table 1. Parameters of solid biomass

\begin{tabular}{|l|c|c|c|}
\hline \multicolumn{1}{|c|}{ Biofuel } & $\begin{array}{c}\text { Calorific value } \\
{[\mathrm{MJ} / \mathrm{kg}]}\end{array}$ & Humidity $[\%]$ & $\begin{array}{c}\text { Density } \\
{\left[\mathrm{kg} / \mathrm{m}^{3}\right]}\end{array}$ \\
\hline Straw & 15.2 & 15 & 120 \\
\hline Woodchips & 17.0 & 35 & 252 \\
\hline Pellets & 19.0 & 10 & 700 \\
\hline
\end{tabular}

a heating season for 222 days a year, 3 rd climatic zone (Rzeszów).

The average heat load factor is $\mathrm{j}_{m}=0.456$ for the designed external temperature $t_{e}=-20^{\circ} \mathrm{C}$ and the average external temperature in the heating season $t_{e m}=1.76^{\circ} \mathrm{C}$. The time of central heating system operation per day is $24 \mathrm{~h} /$ day. The boiler efficiency depending on the type of fuel: woodchips $\mathrm{h}_{k}=88 \%$, pellets $\mathrm{h}_{k}=85 \%$, straw $\mathrm{h}_{k}=82 \%$, average heat transmission efficiency $\mathrm{h}_{c o}=95 \%$. The thermal power for hot water production in each boiler plant is $100 \mathrm{~kW}$. Hot water is used
365 days per year. The hot water transmission efficiency is $\mathrm{h}_{c w}=90 \%$. The annual demand for heat for heating buildings $Q_{a c o}$ and for hot tap water $Q_{a c o}$, including the boiler efficiency (depending on the type of fuel) and the average heat transmission efficiency are shown in Table 2.

\section{RESULTS}

The biofuel consumption was determined on the basis of an annual demand for energy. The highest annual consumption is characteristic for straw, compared to woodchips and pellets, due to its lowest calorific value and fuel density (Fig. 1). An increase in the boiler plant power results in an enhanced biomass consumption. The biomass consumption increases by approximately $87 \%$ and $200 \%$ when the

Table 2. Heat demand for building heating and hot water production

\begin{tabular}{|c|c|c|c|c|}
\hline \multirow{2}{*}{ Biofuel } & Heat power of boiler plant & Hot water $Q_{a c w}$ & Heating $Q_{a c o}$ & Total $Q_{a}$ \\
\hline & {$[\mathrm{kW}]$} & [MWh/year] & [MWh/season] & [MWh/year] \\
\hline \multirow{3}{*}{ Woodchips } & 400 & & 832.6 & 960.1 \\
\hline & 600 & 127.5 & 1665.2 & 1792.7 \\
\hline & 1000 & & 2775.3 & 2902.8 \\
\hline \multirow{3}{*}{ Pellets } & 400 & & 862.0 & 994.0 \\
\hline & 600 & 132.0 & 1723.9 & 1856.0 \\
\hline & 1000 & & 2873.2 & 3005.3 \\
\hline \multirow{3}{*}{ Straw } & 400 & & 893.5 & 1030.4 \\
\hline & 600 & 136.9 & 1789.0 & 1925.9 \\
\hline & 1000 & & 2978.3 & 3115.2 \\
\hline
\end{tabular}

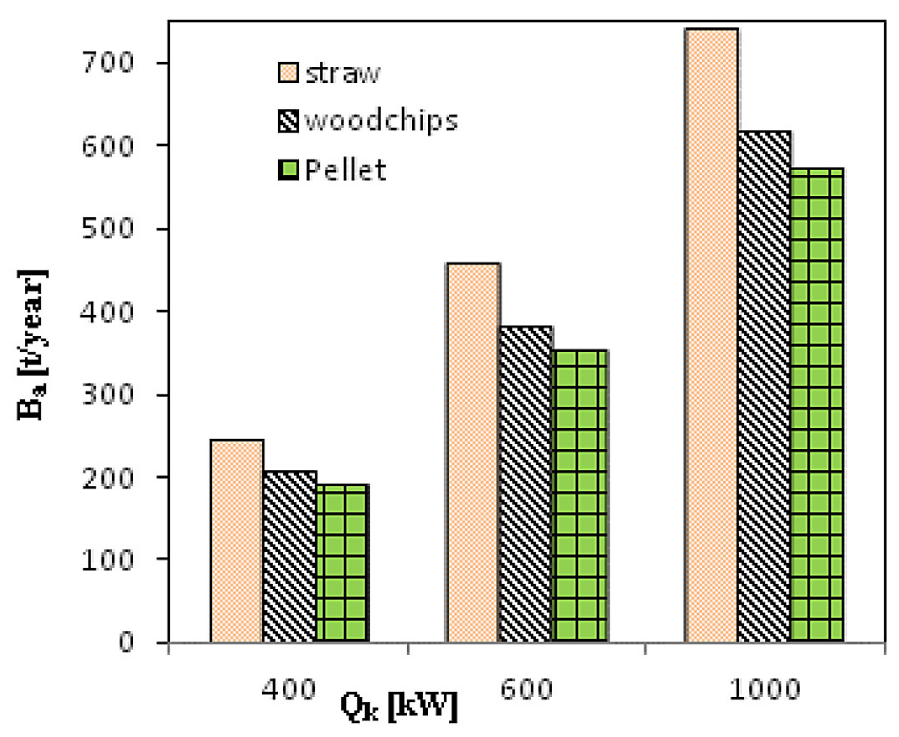

Fig. 1. Biofuel annual consumption in the boiler plant for heating buildings and water 
thermal power of the boiler plant increases by $50 \%$ and $150 \%$, respectively, (from $400 \mathrm{~kW}$ to 600 and $1000 \mathrm{~kW}$ ). The total biomass consumption for production of $1 \mathrm{MWh}$ of heat is highest for straw, amounting to $237 \mathrm{~kg}$ and lowest for pellets, reaching $189 \mathrm{~kg}$.

The type and form of stored fuel affect the size of the storage area. Straw requires the largest storage area (Fig. 2), more than 7 times larger than pellets and about 2.5 times larger than woodchips. The storage area is larger approximately twice and more than 3 times when the thermal power of the plant increases by $50 \%$ and $150 \%$, respectively. The granulated fuel (pellets) needs the smallest storage area compared to the other fuels.

\section{Economical analysis of heat production}

The main element of the heat production cost is the fuel cost. Figure 3 presents the changes in the biomass costs depending on the boiler plant power. The following fuel unit costs were assumed: straw 85 PLN/bale, woodchips $65 \mathrm{PLN} / \mathrm{m}^{3}$ and pellets $280 \mathrm{PLN} / \mathrm{m}^{3}$. The price of diesel fuel of $5.09 \mathrm{PLN} / \mathrm{dm}^{3}$ and fuel loading and unloading costs were included. The biomass cost is determined by the consumption and unit price. In the analysed boiler plants, the annual cost of woodchips $K_{B}$ is from 52.4 thousand PLN to 158.6 thousand PLN and is lower by $34 \%$ from the cost of pellets and by $54 \%$ from the cost of straw.

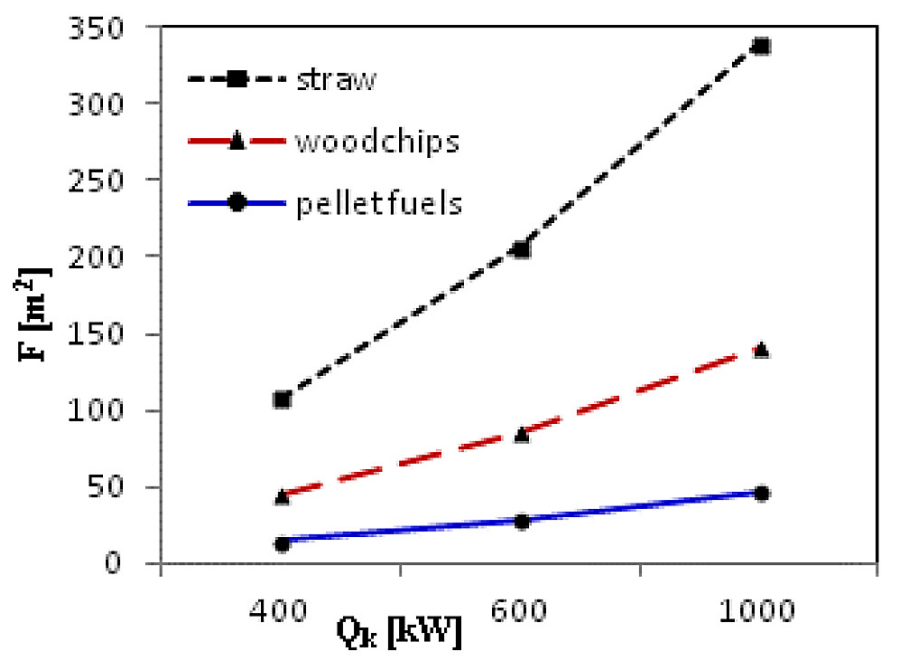

Fig. 2. Storage area in the boiler plant using woodchips, pellets and straw

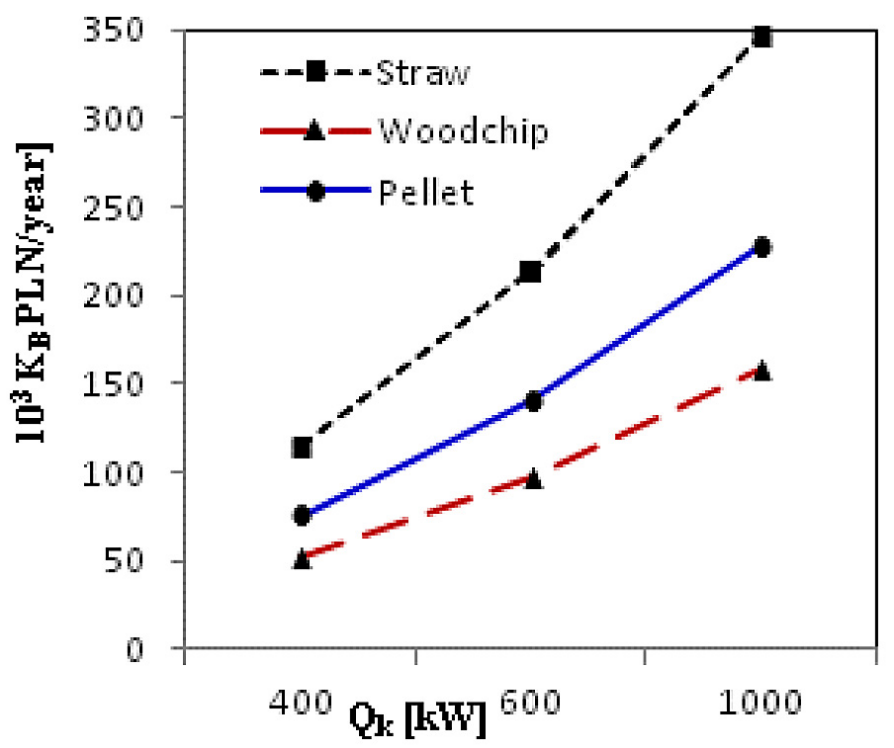

Fig. 3. Biomass cost $\mathrm{K}_{\mathrm{B}}$ 
The total cost of fuel supply includes the cost of consuming the fuel used for transport (diesel fuel) and loading and unloading costs. It was assumed that the boiler plant is located $30 \mathrm{~km}$ from the place of acquiring biomass. In this case, the lowest transport cost $K_{D}$ is for granulated fuel (Fig. 4) and it is lower by $89 \%$ from the cost of straw distribution. The percentage of the biofuel distribution cost in total costs was from about $2 \%$ (pellets) to more than 9\% (straw), (Fig. 8). The total cost of heat production $U$ for straw, pellets and woodchips was approximately 122, 77 and 58 PLN/MWh, respectively (Fig. 5, 6 and 7).

Woodchips are the biofuel with the lowest heat production cost, especially for the heat sources with medium powers. The availability of woodchips on local fuel markets and their stable price allow assuming that it is an optimum fuel in heat production and in co-generative systems (heat and electricity production) in the several hundred kilowatt boiler plants. However, the fuel requires significant storage areas.

The granulated fuel is definitely preferred in the boiler plants with low thermal powers. It does not require large storage areas, is easy to transport and has low distribution cost. The fuel cost is very significant in determining the profitability of using biomass fuel. The present biofuel prices are rising, especially the pellet prices (in 2019 the price for one ton was 800-900 PLN

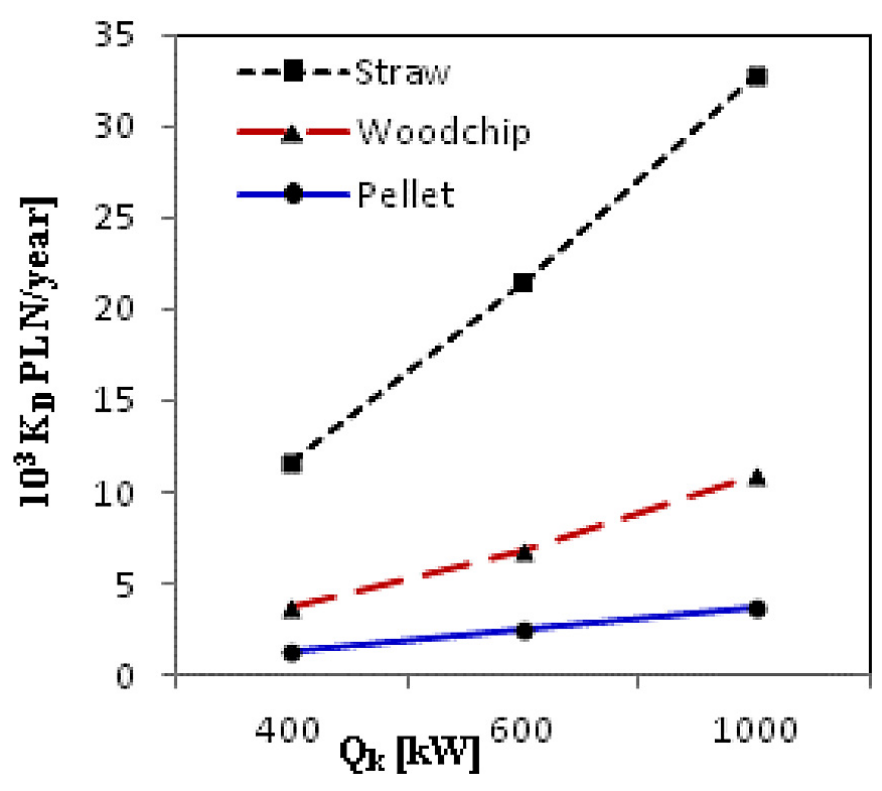

Fig. 4. Cost of biomass transport $\mathrm{K}_{\mathrm{D}}$

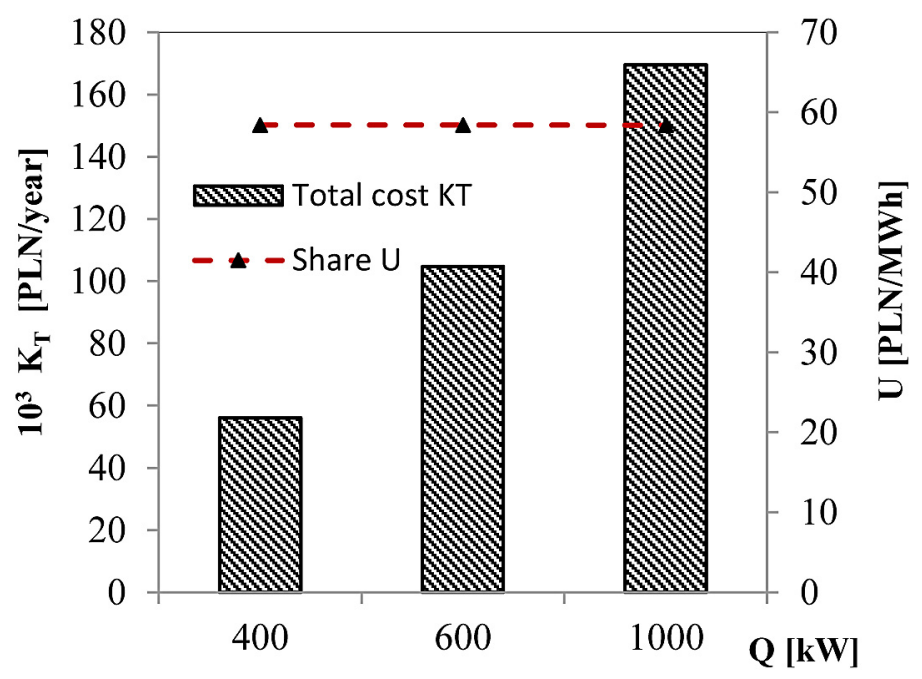

Fig. 5. Total cost and share of costs in the production of heat from woodchips 


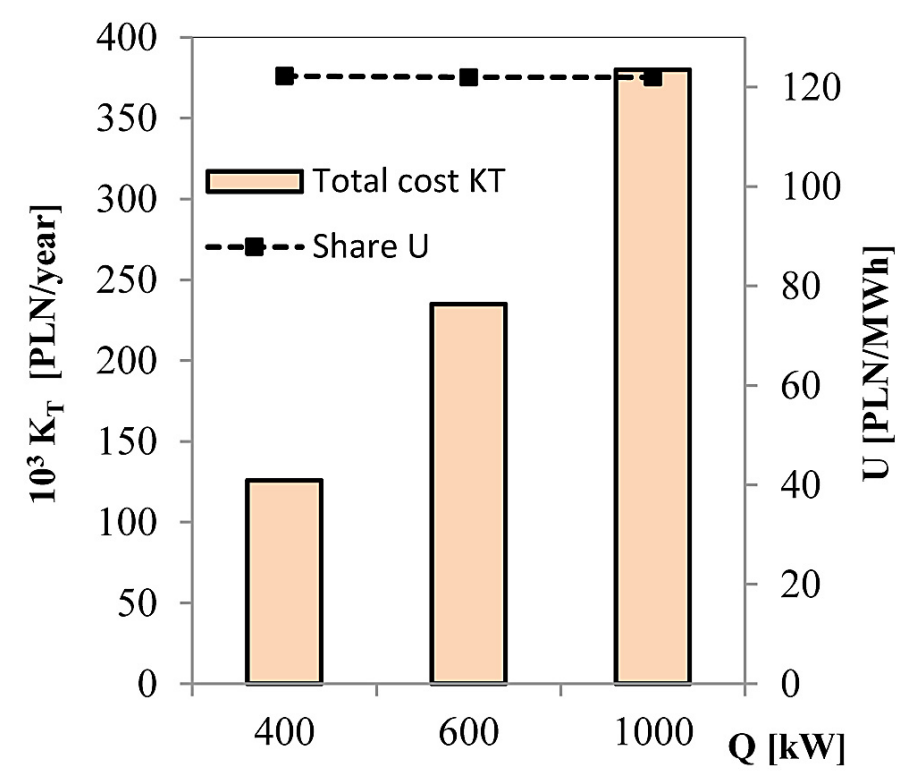

Fig. 6. Total cost and share of costs in the production of heat from straw

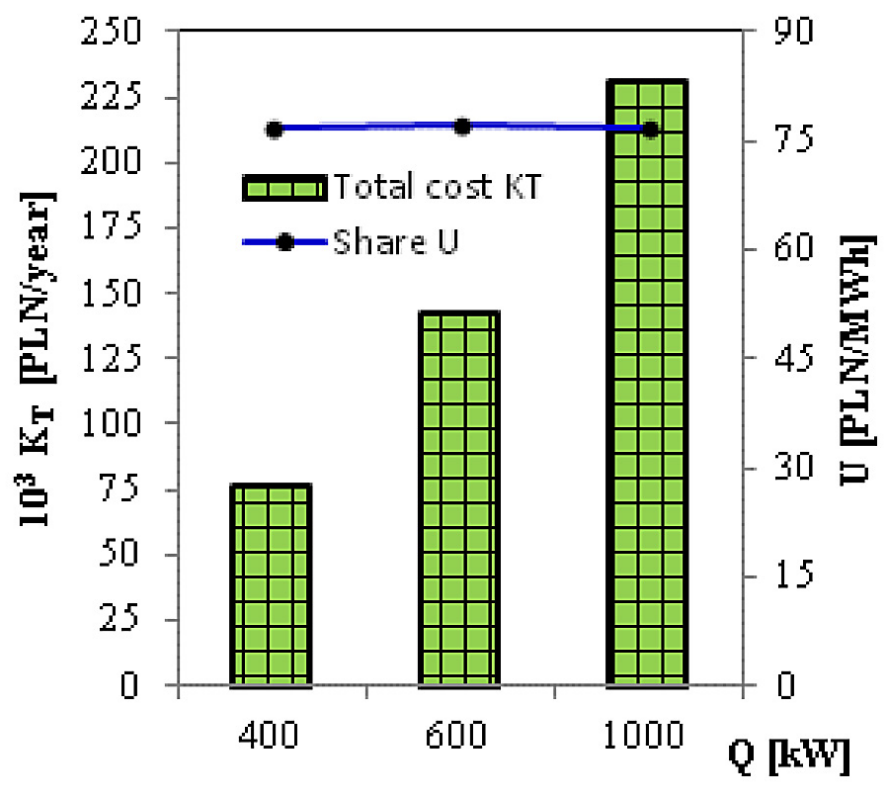

Fig. 7. Total cost and share of costs in the production of heat from pellets

[www.ebiomasa.pl/gielda-biomasy 2019]). That results from a higher demand for biomass due to the exchange of the coal sources of heat to the sources heated with biomass (class 5 boilers) made as a part of various programmes, such as the Clear Air Programme, and the possibility to get subsidies and soft loans.

\section{CONCLUSION}

The presented analysis of biomass management in a boiler plant producing heat for heating buildings and water allowed determining the costs of heat production from solid biomass. The calculations were performed for straw, woodchips and pellets, representing three typical forms of solid biomass: compressed, crushed and granulated. It was shown that the annual demand for heat is lowest for woodchips and pellets due to the high efficiency of production devices. In turn, the granulated biofuel has the lowest consumption and needs the smallest storage area. The percentage of the biofuel distribution cost (distance of $30 \mathrm{~km}$ ) in the total costs was from $2 \%$ to more than $9 \%$ and it is lowest for pellets. The heat production cost 


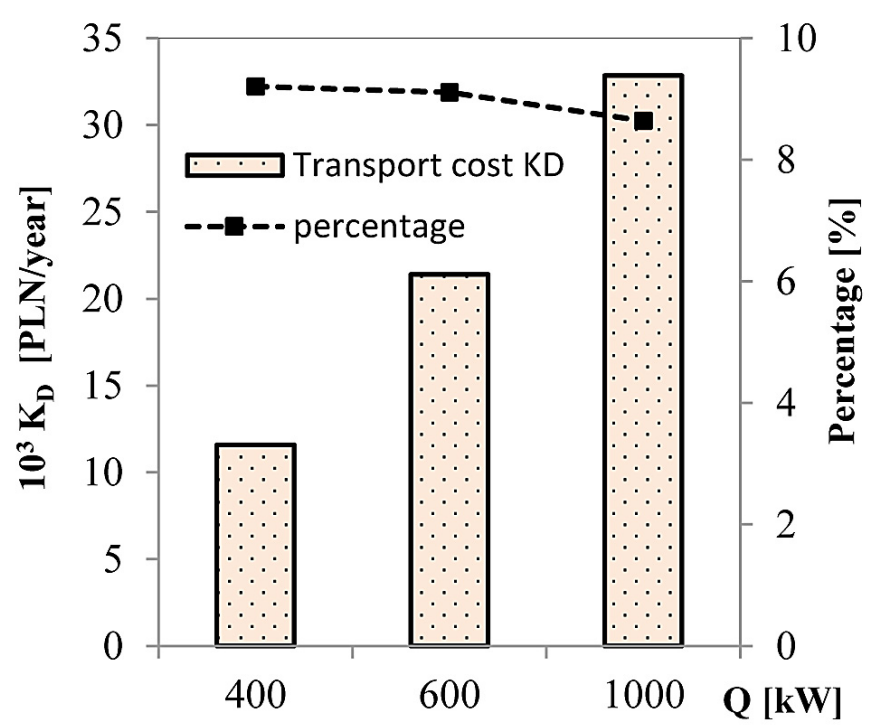

Fig. 8. Transport cost and percentage of transport cost in the total cost for straw

depends mainly on the fuel cost and significantly determines the cost-effectiveness of the system. The energy parameters of granulated biomass, low storage cost and high efficiently of boilers with low contamination emissions compared to other types of biomass allow recognizing it as the most effective fuel in heat production.

\section{REFERENCES}

1. Renewables 2019. Global Status Report. REN21, 2019.

2. Renewable Energy in 2017. 2018a. Information Bulletin. 16.11.2018. GUS.

3. Renewable Energy in 2017. 2018b. Statistical
Analyses. GUS, Warsaw.

4. Renewable Energy Act of 20 February 2015. (Dz.U. of 2018 no 2389 and 2245, of 2019 no 42, 60, 730).

5. Bentsen N.S., Felby C., Thorsen B.J. 2014. Agricultural residue production and potentials for energy and materials services. Progress in Energy and Combustion Science. 40 (2014), 59-73.

6. Agriculture in 2018 Statistical Analyses. 2019. GUS, Warsaw.

7. http://www.lasy.gov.pl/. Access 14.08.2019.

8. Rentizelas A., Tolis A., Tatsiopoulos I.P. 2009. Logistics issues of biomass: The storage problem and the multi-biomass supply chain. Renewable \& Sustainable Energy Reviews, May 2009. 13(4), 887-894.

9. http://www.ebiomasa.pl/gielda-biomasy/ Access 19.07.2019. 